\title{
INVESTIGACIÓN
}

Recibido: 15/02/2018 --- Aceptado: 30/05/2018 --- Publicado: 15/09/2018

\section{CONSTRUCCIONES Y TRANSGRESIONES DE LA MÚSICA EN LAS SERIES DE AMBIENTACIÓN HISTÓRICA}

\section{Constructions and transgressions of music in the series of historical background}

Teresa Piñeiro-Otero. Universidade da Coruña. España.

teresa.pineiro@udc.es

\section{RESUMEN}

La música desarrolla un papel esencial en la experiencia de visionado del espectador. Aunque en el relato audiovisual la imagen es el foco consciente de la atención, la música aporta una serie de efectos, sensaciones o significaciones que aportan valor a la narración y se proyectan como parte del discurso visual. Dentro de las funciones de la música audiovisual destaca la de crear atmósferas convincentes de tiempo lugar. Esta función de "color local" adquiere particular relevancia en las series de época debido a su posibilidad de dotar de realismo a su ambientación. En un momento en que las producciones televisivas han incrementado su calidad técnica y artística la selección/creación y empleo de la música ha adquirido una especial proyección en la construcción del relato audiovisual. En este sentido el objeto del presente trabajo ha sido el de efectuar una aproximación al uso de la música en las series de época, especialmente en lo que se refiere a los temas preexistentes. Una aproximación que ha permitido señalar diversas tendencias en la concepción del scoring atendiendo a su fidelidad.

\section{PALABRAS CLAVE}

Música; Quality TV; Series televisivas; Scoring; Selección musical; Composición original; Ficción de época

\begin{abstract}
Music plays an essential role in the viewing experience of the viewer. Although in the audiovisual story the image is the conscious focus of attention, music provides a series of effects, sensations or meanings that add value to the narrative and are projected as part of the visual discourse. Among the functions of audiovisual music stands out the one of creating convincing atmospheres of time or place. This function of "local color" acquires particular relevance in the series of epoch due to its possibility of giving realism to its setting. At a time when television productions have increased their technical and artistic quality, the selection / creation and use of music has acquired a special projection in the construction of the audiovisual story. In this sense, the object of the present work has been to make an approximation to the use of music in the previous time series, especially in regard to pre-existing themes. An
\end{abstract}


approach that has allowed to point out different trends in the design of the scoring paying attention to their fidelity.

\section{KEY WORDS}

Music; Quality TV; TV series; Scoring; Musical selection; Original composition; Vintage fiction

\section{CONSTRUÇÕES E TRANSGRESSÕES DA MÚSICA NAS SÉRIES DE AMBIENTAÇÃO HISTÓRICA}

\section{RESUME}

A música desenvolve um papel essencial na experiência da visão do espectador. Embora no relato audiovisual a imagem é o foco consciente da atenção, a música aporta uma série de efeitos, sensações ou significações que aportam valor a narração e se projetam como parte do discurso visual. Dentro das funções da música audiovisual destaca a de criar atmosferas convincentes de tempo e lugar. Esta função de "cor local" adquire uma particular relevância nas series de época devido a sua possibilidade de dotar de realismo a sua ambientação. Em um momento em que as produções televisivas incrementaram sua qualidade técnica e artística a seleção/criação o emprego da música adquiriu uma especial projeção na construção do relato audiovisual. Neste sentido o objetivo do presente artigo foi efetuar uma aproximação ao uso da música em series de época, especialmente no que se refere aos temas pré-existentes. Uma aproximação que permitiu assinalar diversas tendências na concepção da scoring atendendo a sua fidelidade.

\section{PALAVRAS CHAVE}

Música; Quality TV; Séries televisivas; Scoring; Seleção musical; Composição original; Ficção de época

\section{Cómo citar el artículo}

Piñeiro Otero, T. (2018). Construcciones y transgresiones de la música en las series de ambientación histórica. [Constructions and transgressions of music in the series of historical background] Vivat Academia. Revista de Comunicación, no 144, 95-110. doi: http://doi.org/10.15178/va.2018.144.95-110. Recuperado de http:/ / www.vivatacademia.net/index.php/vivat/article/view/1110

\section{INTRODUCCIÓN}

La música constituye un elemento clave de nuestra experiencia como espectadores. Si bien en un relato audiovisual es la imagen la que capta de una forma consciente la atención es el discurso sonoro el que aporta una serie de efectos, sensaciones y significaciones. Una aportación que enriquece la narración y, por la magia audiovisual, se percibe como propias de la imagen (Gorbman, 1980; Brown, 1994).

Este fenómeno, para el que Chion (1993) acuñó el término audiovisión, es fruto de un complejo sistema perceptivo que tiene en la música su principal aliado. En la 
pantalla y sus aledaños imagen y sonido establecen un maridaje perfecto aun cuando ambos discursos -visual y sonoro- parezcan divergir $u$ ofrecer contenidos contradictorios.

En la llamada tercera edad de oro de la televisión se está produciendo una eclosión de nuevas formas de consumo (y disfrute) de los contenidos televisivas. Se trata de la emergencia de los "must see TV-shows" (Jancovich y Lyons, 2003) especialmente representados por series televisivas cuya factura cuidada, prácticamente cinematográfica, suscita pasiones por los contenidos y sus artífices. La Quality TV ha conllevado la expansión del fenómeno fan del elenco de actores a directores, productores e incluso de compositores o sound designers.

En este contexto es habitual el traspaso de profesionales y artistas de la gran pantalla a la pequeña, que nunca hasta ahora había sido tan pequeña (hasta 4,5 pulgadas en la palma de la mano) ni tan grande a la vez (estilísticamente hablando). Así desde sus primeros frames The Crown (Netflix, 2016-) impacta en el espectador con una música poderosa que lleva el sello del oscarizado Hans Zimmer.

Si bien el "cameo" de compositores de cine en la televisión no es exclusivo de la Quality TV, véase por ejemplo el tema de cabecera de Rich man, poor man (ABC, 1976) de Alex North o la participación de Ennio Morricone en diversas miniseries italianas, nunca como este momento la ambientación musical de las series desarrolló un papel tan relevante en su recepción.

Como señala Calderón, Gusterns y Durán (2016) en el relato cinematográfico sonido e imagen están sujetos a los tres actos clásicos de la trama argumental (presentación-nudo-desenlace), respaldando las emociones y acciones de los personajes de forma sustantiva y diegética; en la ficción seriada esta estructura se diluye en episodios y temporadas.

Autores como T-Bone Burnett, Bryan Reitzell o Max Richter, con una importante trayectoria en el cine, han participado en la composición y/o selección musical de series como True Detective, (HBO, 2014- ) Hannibal (NBC, 2013-2015) o The Leftovers (HBO, 2014-2017) cuya banda sonora las eleva al estatus de arte. La expresividad de la ambientación musical en estas series responde una efectividad estructural, basada en una sonoridad y diversidad textural, así como en la intertextualidad implícita en los temas prexistentes.

Estas series presentan un diseño global de la banda sonora generando en los espectadores una experiencia más estética e inmersiva en la línea señalada por (Richardson y Gorbman, 2013, p. 29). Uno de los aspectos geniales del sonido en esta era dorada de la serialidad es la concepción holística tanto del discurso audible como del relato audiovisual en general. Por una parte el scoring de la serie integra música música, efectos, voces, reverberación del espacio o texturas sonoras en un continuum sonoro (Stilwell, 2001); por otra contribuye a la construcción del paisaje visual así como de ideas y sensaciones complejas de comunicar únicamente con imágenes (Kelly, 2016).

De este modo la música detenta una participación activa en la interpretación de la imagen hasta el punto de ser esencial para la comprensión del relato. Así sucede, por ejemplo, en el caso de Hannibal (2013-2015) serie en la que el empleo e temas del repertorio clásico añade diversas capas de lectura (Piñeiro-Otero, 2016). 


\subsection{La construcción de paisajes sonoros}

En una suerte de sinestesia el discurso sonoro -música, atmósferas y texturas sonoras- logran comunicar, modificar o amplificar el contenido de la imagen. El papel del sonido en la construcción del relato audiovisual dota de gran relevancia al paisaje sonoro o soundscape yuxtaponiéndolo en muchas ocasiones a la línea visual de la serie.

Desde su irrupción en la década de los 60, de la mano de Schafer, el término soundscape remite a una dialéctica entre aspectos naturales y culturales. Del mismo modo que un "paisaje está constituido por historias, ideologías y prácticas de visionado, el paisaje sonoro implica la escucha como una práctica cultural" (Samuel et al., 2010, p. 330).

La estrecha relación entre los paisajes sonoros y la cultura resulta interesante desde la perspectiva del relato audiovisual dada la posibilidad de producir soundscapes artificiales centrándose en determinados sonidos o en sus características para crear -o recrear- la realidad material donde tiene lugar el relato o la imagen concreta que se quiere suscitar en la mente del espectador (Chion, 1993; Samuel et al., 2010).

Estas construcciones han afectado a nuestra percepción de la realidad hasta el punto de que podemos describir cómo suena un determinado lugar del mundo aun cuando no hemos tenido la oportunidad de desplazarnos hasta allí y del hecho de que no nos sentimos identificados con la construcción musical que cine y televisión han desarrollado de nuestro territorio.

Incluso podemos tener una idea bastante vívida de cómo sonaban épocas pasadas, algunas de ellas anteriores a la escritura musical gracias al diseño y reiteración de patrones musicales.

En este sentido diversos trabajos han explorado el rol de la música en la construcción de espacios a partir del lugar de la fuente, su relación con los personajes o el significado de dichas composiciones -su forma, instrumentación o recursos compositivos- para los espectadores (Gorbman, 1980; Chion, 1993; Lack, 1999; Altman, 2007).

El objeto del presente trabajo ha sido el de profundizar el empleo de la música original, y especialmente, pregrabada en el ámbito de las series de época dentro de la Quality TV. Una aproximación que permite señalar diversas tendencias en la concepción del scoring de esta tipología de series atendiendo a la dimensión fidelidad.

\subsection{La música en la ambientación de las series}

El scoring de las producciones televisivas suele contener dos tipologías de música: la música fílmica, habitualmente de carácter instrumental, formada por pequeñas composiciones y acordes que carecen de entidad al margen de la imagen y aquellos temas independientes, como canciones, que pueden ser originales o pregrabadas.

Sea cual sea su forma desde el momento en el que la música que aparece en pantalla -como señalan Torrelló y Durán (2014)- incide en la creación y definición de la diégesis fílmica así como en la construcción del discurso audiovisual desde 
diversas perspectivas como formal, narrativa, poética, dramatúrgica o psicológica, entre otras.

Siguiendo a Copland (1988) una de las principales funciones de la música en el cine es la de crear una atmósfera convincente de tiempo y lugar. Esta función que Prendergast (1992) denomina color local se basa en la intención y efecto -de una determinada música- de suscitar un espacio en la mente del espectador a partir de determinadas características tonales, expresivas o evocadoras. Como recuerda Whitraker (2012, p. 116) "La instrumentación y voz de cada canción tiene su propio timbre y fraseos, al igual que la mise-en-scène tiene su textura, color y formas".

La función de color local de la música opera sobre la dimensión de la fidelidad del sonido: las composiciones pueden ser de una época concreta o constituir partituras originales que emulen sus particularidades sonoras. Así en el diseño sonoro de las series de época podemos escuchar una selección de canciones que esbozan un panorama de la música del momento (ya sea de la época o anteriores) que podrían formar parte del espacio en el que transitan los personajes, y/o nuevos temas con reminiscencias de forma, estilo, instrumentación o temática a dichas canciones.

Esta dualidad entre temas preexistentes y música original, presente en la mayoría de las series de época, suele reflejar una dupla concepción de la música atendiendo al lugar de la fuente sonora: así los temas de repertorio suelen sonar dentro del espacio (música de pantalla) -como salones de baile, radios o gramófonos, música ambiente, etc.- mientras la música original suele acompañar a la imagen proponiendo su lectura (música de foso) Se trata de una organización tradicional de esta música pero no la única así en series como Pan Am (ABC, 2011-2012) existen secuencias en las que canciones de moda del momento discurren paralelas a la imagen, sin incidir aparentemente en éstas, mientras en otras como Marco Polo (Netflix, 2014-2016) la música original se disfraza de tradicional para acompañar los espacios del Kublai Khanato.

Más allá de la capacidad de la música de situarnos como espectadores en un determinado contexto temporal la selección de temas preexistentes puede determinar la decodificación de una secuencia audiovisual y por ende su valor añadido sobre la imagen (Chion, 1993; Powrie \& Stilwell, 2006). En estos casos el impacto de la selección musical depende directamente de su reconocimiento así como de la carga cultural que acarrean dichas composiciones, especialmente de las canciones cuyo contenido textual aporta nuevas capas de lectura y significación (Richardson y Gorbman, 2013).

Parafraseando a Wright (2003) en muchos casos la música pregrabada viene con sus propios contornos referenciales como sucede, por ejemplo, con The man in the hightcastle (Amazon, 2015- ). Esta serie se sitúa en un pasado distópico, en los años posteriores a una II Guerra Mundial en la que Alemania y Japón vencieron al bando aliado. La selección musical de la serie recoge composiciones de los años 60 que podrían formar parte de otras producciones de vocación realista como Pan Am (ABC, 2011-2012), Masters of Sex (Showtime, 2013-2016) o Mad Men (AMC, 2007-2015).

En la cabecera de The Man in the High Castle (Amazon, 2015- ) se presenta la sobreimpresión de mapas, diversos símbolos de la Alemania Nazi y Japón o de aviación bélica sobre algunos de los monumentos más insignes de Estados Unidos como la estatua de la libertad o alguna de las caras del monte Rushmore. 
Estas imágenes van acompañadas del tema Edelweiss interpretado -casi susurradopor una voz femenina sobre una base instrumental muy simple. Este tema compuesto por Rodgers y Hammerstein para la obra musical The sound of music (1959) está estrechamente ligado a la resistencia patriótica austríaca frente a las presiones del régimen nazi. De hecho algunos espectadores podemos asociarlo a Georg von Trapp y, más concretamente, a la fuga de su familia de los nazis al final de la adaptación cinematográfica del musical que en España se denominó Sonrisas y lágrimas (1965).

La apertura de la serie televisiva con esta canción también puede remitir a ese hombre en el castillo que -como la flor alpina-crece en un lugar elevado y resiste.

Siguiendo a Whiteley (2004) la música permite definir espacios y épocas debido a su papel en la construcción de identidades nacionales y de marcos culturales de referencia. Una capacidad potenciada por la cultura audiovisual, que ha popularizado determinadas conexiones músico-temporales y que se retroalimenta de éstas.

Por ejemplo la construcción del discurso musical es similar en series como Vikings (History Channel, 2013- ) o The Last Kingdong (BBC, 2015 -): el scoring de ambas series se compone una línea vocálica que no aspira a la inteligibilidad sobre una base musical simple, con pocos instrumentos, y un peso importante de la percusión. La principal diferencia entre ambas músicas radica en el contenido de la línea vocálica: una voz femenina de timbre medio-agudo subraya el carácter individual de la epopeya de Uhtred de Bebbanburg, el protagonista de The Last Kingdom, mientras un coro de voces graves, masculinas, recuerda la relevancia de la empresa de Ragnar Lothbrok para el pueblo vikingo.

Ambas series tienen lugar en una época (S.IX) en la que la notación musical [occidental] se encontraba en estado incipiente y se vinculaba exclusivamente al ámbito religioso cuestión que, en la serie, va a ayudar a construir la contraposición entre el cristianismo [de cortes, monasterios y catedrales] y los pueblos "bárbaros" del norte.

La contraposición de dos culturas a partir de la música también se observa en otras producciones televisivas ambientadas en épocas más recientes. En estos casos se suele apelar a estereotipos culturales como por ejemplo en la forma, estilo e instrumentalización de la música que envuelve a la acción (tanto de foso como pantalla) pero también a canciones que acarrean su propia intertextualidad.

Así en Outlander (Sony Pictures televisión, 2014-) la gaita escocesa se convierte en un timbre preponderante que sirve de anclaje histórico en el viaje de Claire Beuchamp desde 1945 en los meses posteriores a la II Guerra Mundial, cuando viaja por las Highlands escocesas con su marido siguiendo el rastro de un antepasado, a 1743 en una época convulsa, previa al último levantamiento jacobita, marcada por el continuo enfrentamiento entre los clanes escoceses y el gobierno británico. La conexión entre el scoring original de la serie con la música tradicional tiene su máximo exponente en la apertura de la serie en la que la voz de Raya Yarbrough canta el poema Sing me a Song of a lass that is Gone de Louis Stevenson sobre la base melódica de The Skye Boat Song, canción popular escocesa.

Del mismo modo en Rebellion (RTÉ, 2016-), que relata los hechos en torno al Levantamiento de Pascua (1916) a partir de una serie de personajes ficticios, el 
espectador se ve envuelto por un scoring con rasgos y temas de la música popular irlandesa.

Ambos tipos de música -escocesa e irlandesa- han impregnado el cine de Hollywood (al igual que los estereotipos de pueblos que construyen) y, por ende, con gran arraigo en nuestra cultura audiovisual.

En lo que se refiere al empleo de temas de repertorio para ilustrar una determinada cultura-época y que acarrean sus propias lecturas, resulta especialmente interesante la serie Boardwalk Empire (HBO, 2010-2014). Esta producción televisiva se ambienta en Atlantic City de los años 20 -en plena Ley Seca- para relatar la vida de un contrabandista de alcohol, la construcción-defensa de su imperio y la relación que tiene con otras familias del hampa. En la presentación de los líderes o principales sicarios de las familias es frecuente la inclusión de temas preexistentes que van a reforzar la construcción de su origen: Así Danny Boy se asocia al protagonista Nucky Thompsom (de ascendencia irlandesa), especialmente después de que otro pers onaje -Bill McCoy- cantase una variación de la letra durante una fiesta para elogiar al gángster.

Otra asociación de este estilo la encontramos en el primer episodio de la serie cuando Big Jim Colosimo, cabeza de la mafia de Chicago, pone en la gramola el tema O Lola en la voz de Enrico Caruso. La elección de tema e intérprete podría señalar un gusto musical refinado, en la línea señalada por Visa (2011), pero va más allá.

Este tema, que funciona como un fuera de campo extendido en una secuencia de ajuste de cuentas entre mafiosos que se salda con la muerte del propio Colisimo, forma parte de la ópera Cavalleria Rusticana de Pietro Mascagni: una obra clásica en la construcción audiovisual de personajes italoamericanos. Por ejemplo el Intermezzo de esta ópera acompaña el ocaso de Michael Corleone y familia en el final del Padrino III (Coppola, 1990), la presentación de Jake Lamota en Toro Salvaje (Scorsese, 1980).

\section{OBJETIVOS}

En los últimos años se ha apostado por producciones televisivas que se ambientan o recrean una determinada época. Series como Mad Men (AMC: 2007-2015), Boardwalk Empire (HBO: 2010-2014), Los Tudor (Showtime: 2007-2010), Vikings (History Channel, 2013- ), Marco Polo (Netflix, 2014-2016), The Americans (FX, 2013 -) o Roma (HBO: 20052007) han trasladado su acción a determinados momentos del pasado ya con una vocación histórica ya como un recurso más para una mayor proyección del relato.

Así mientras The White Queen (BBC, 2013) o The Crown (Netflix, 2016-) relatan hechos reales, aún con algunas licencias creativas, otras como Nicholas Le Floch (France 2, 2008-), Pan Am (ABC, 2011-2012), Poldark (BBC, 2015- ), e incluso Las Chicas del Cable (Netflix, 2017- ) o Downton Abbey (ITV, 2010-2015) muestran personajes y situaciones ficticias que integran algún hecho o personaje histórico para dotarlas de mayor realismo y -finalmente- un tercer tipo simplemente seleccionan una época concreta para dar respaldo al relato así sucede con American Horror Story Asylum o Freak Show (FX, 2012-2013 y 2014-2015, respectivamente) Godless o Alias Grace (ambas producciones de Netflix, 2017).

Si bien en estas series se ha cuidado el diseño de producción al máximo para aportar realismo al relato, incluso en producciones fantásticas como Penny Dreadful 
(Showtime, 2014-2016) o Strangers Things (Netflix, 2016-), en el caso de su ambientación musical se pueden observar diversas decisiones creativas que van desde una apuesta por el realismo a su transgresión con finalidad expresiva.

En este sentido el presente trabajo ha tenido como objetivos:

- Efectuar una aproximación al empleo de la música en las series ambientadas en épocas pasadas.

- Profundizar en los principales usos y funciones del discurso musical en la construcción de este tipo de ficción televisiva.

\section{METODOLOGÍA}

Para abordar el objeto de estudio, la música en las series de la Quality TV. ambientadas en momentos del pasado se desarrolló un análisis del discurso musical en varias etapas.

En la primera etapa se llevó a cabo una búsqueda de series "de época" en el listado de galardones Bafta y Emmy de la última década (2006-2016). En busca de una mayor exhaustividad esta búsqueda se amplió al catálogo de los principales servicios de suscripción Premium de video on demand con servicio en España (HBO, Netflix y Movistar+).

En una segunda etapa se llevó a cabo el visionado de diversos episodios de estas series (episodio piloto y otro seleccionado al azar), reiterando la revisión del material en aquellos fragmentos en los que se introdujese música.

Con la finalidad de conocer papel de la música y su valor añadido respecto al discurso visual se analizaron estos fragmentos empleando para ello el método de ocultadores (Chion, 1993).

En el caso de la música de repertorio se optó por el empleo Shazam para obtener información de las canciones -título, intérprete, año, etc.- y determinar su coherencia con el momento histórico recreado en la ficción. Una vez identificados los temas se efectuó una búsqueda pormenorizada de cada uno para conocer usos previos y vinculaciones culturales, así como un análisis crítico de discurso de las letras de canciones la finalidad de profundizar en sus posibles lecturas.

\section{RESULTADOS}

El incremento de los recursos y posibilidades técnico-expresivas en el desarrollo de las series de televisión ha posibilitado la recreación de épocas pasadas con demostrada solvencia. Esta capacidad creativa, anteriormente reservada al cine, ha permitido a los espectadores viajar a épocas pasadas y sumergirse en relatos de ambientación verídica aún en aquellas series que carecen de vocación realista. Así sucede por ejemplo, con Strangers Things, cuya acción se sitúa en el condado Hawkins de Indiana, EE.UU., durante los años 80.

A la hora de recrear un determinado momento histórico de forma realista las producciones televisivas pueden optar por dos tipologías diferentes de música: emplear temas preexistentes del momento o acudir a composiciones originales cuyo estilo o instrumentación respondan a las expectativas que tenemos como espectadores sobre la música de la época. 
Si con la selección de músicas preexistentes el sound designer -o equivalentepretende el realismo, a partir de los conocimientos y recuerdos de los espectadores, con las composiciones originales actúa en el plano de la fidelidad apelando a las expectativas del público a partir de la emulación de determinadas características musicales. Ambos tipos de música -preexistentes y original-pueden constituir el discurso musical de la serie de forma individual o -más habitualmente- como una mezcla de ambas.

En cualquier caso, recuerdos y expectativas, están importantemente influenciados por la cultura audiovisual.

\subsection{La selección de temas preexistentes}

La integración en el scoring de temas del momento, o anteriores susceptibles de tener presencia en los espacios de la serie, constituye uno de los modos más eficaces de ambientación realista de una determinada época. Si bien se trata de una fórmula que puede aplicarse a diversos contextos espacio-temporales es especialmente eficaz en la recreación de la segunda mitad del siglo XX.

Esta eficacia comunicativa radica fundamentalmente en dos aspectos: por una parte la existencia de una industria musical que ha acelerado los tiempos de producción y contenidos de temas e intérpretes, lo que permite una vinculación temporal muy ajustada; por otra la relación de afectividad con los espectadores debido a la presencia de algunas de estas canciones en su socialización primaria, como éxitos musicales (o audiovisuales) de etapas anteriores de su vida o incluso por su presencia en las radiofórmulas musicales (formatos estilo Oldies o Nostalgia).

Así, por ejemplo, la selección musical de The Americans (FX, 2013 -) nos sitúa a comienzos de la década de los 80 . La inclusión de temas estrenados a de los 70 y en los dos primeros años de 80 adquiere particular relevancia en el primer episodio -que contiene una mayor selección musical- para apelar al reconocimiento del momento entre el público y potenciar su realismo.

Por su parte la selección musical de Boardwalk empire (HBO, 2010-2014) nos sitúa en los años 20 con la integración de temas del momento con otros anteriores, perfectamente tratados para una mayor adaptación a los espacios y a las fuentes de donde provienen (gramolas, pianos, teatros, espectáculos de vaudeville...).

La familiaridad con la época, debido a los numerosos relatos audiovisuales que se ubican en Estados Unidos en el momento de la Ley Seca, nos ha llevado a forjar una idea de la sonoridad del momento y Boardwalk empire se ajusta a la perfección: efectúa un recorrido por los estilos de moda en los "roaring twenties" como el jazz y blues, temas de vaudeville así como música popular, ópera y otros géneros que contribuyen a la caracterización de los personajes.

Si bien la serie efectúa una impecable aproximación a música de la "era de la Prohibición" y a las primeras grabaciones de Estados Unidos gracias a la 
colaboración de Archeophone Records ${ }^{1}$ (Schwachter, 2010), no resulta posible fijar una ubicación temporal tan exacta como en The Americans (FX, 2013 -).

La dificultad de los oyentes de concretar temporalmente determinados temas y estilos musicales, especialmente de aquellos anteriores a la creación de listas adult contemporary, ha sido aprovechado desde una perspectiva creativa por producciones televisivas como Manhattan (WGN, 2014-2015), que versa sobre el célebre proyecto. Esta serie ambientada en 1943 en Los Álamos, Nuevo México, cuenta con una selección musical variada con temas del momento y otros posteriores Let's Go Home de The Staple Singers (1960), I Know Who Threw the Whiskey In the Well de Bull Moose Jackson (1946), o I Don't Want to Set the World On Fire de The Ink Spots (1947), entre otros. La proximidad temporal de estos temas ha propiciado que, a pesar de su anacronismo, no se vea comprometido el realismo de su ambientación musical.

\subsection{Una llamada a la nostalgia}

Mad Men (AMC, 2007-2015), Pan Am (ABC, 2011-2012) o Masters of Sex (Showtime, 2013-2016) ofrecen un recorrido por la nostalgia, también musical. La inclusión de determinados temas funciona como anclaje históricos al igual que algunos eventos noticiosos a los que asisten o comentan los personajes -asesinato de John Fitzgerald Kennedy, de Martin Luther King, la llegada a la luna... - que aportan mayor realismo a la construcción del momento histórico (décadas 50-60).

A pesar que cada una de las series presentan sus propias particularidades a la hora de seleccionar la música como la vinculación con el momento psicológico de los personajes en Mad Men, con la situación como Masters of Sex, o con la temática vueloviaje en Pan Am, su scoring constituye un muestrario de temas-intérpretes míticos del momento como Hound dog de Elvis Presley, Blue Skies de Ella Fitzgerald, Just One More Chance de Billie Holiday, The Twist de Chubby Checker, My Way de Frank Sinatra, o (I can't get no) Satisfaction de The Rolling Stones y Tomorrow Never Knows de The Beatles, entre otros.

En el caso de Mad Men (AMC, 2007-2015), además, se introduce una nueva perspectiva de la música: la música publicitaria. Así en los despachos de la agencia publicitaria se encuadran algunos jingles que pueden ser reconocidos por la audiencia el más famoso es la canción del spot televisivo de Coca Cola con el que se pone punto y final a la serie: I'd like to buy the world a Coke, en España Al mundo entero quiero dar (McCann-Erickson, 1971).

En aquellos casos en los que se apela a un pasado próximo vivido por la audiencia, o por una parte de ella, la inclusión de canciones de la época además de un ingrediente para el realismo de la serie supone una llamada al recuerdo y a la emoción de los espectadores. Así la selección de canciones de Strangers Things (Netflix, 2016-) supone un revival de los 80 con temas como Africa de Toto, Hazy Shade of Winter de The Bangles o Sunglasses at Night de Corey Hart -entre otros- que se mezclan con el scoring original compuesto por Michel Stein y Kyle Dixon. Si bien la

\footnotetext{
1 Productora musical especializada en rescatar, preservar y contextualizar las grabaciones más antiguas del mundo.
} 
música de esta serie presenta algún anacronismo de carácter creativo no se percibe como tal por los espectadores. Del mismo modo Hall and Catch Fire (AMC, 2014-2017) nos presenta otra perspectiva de la música de los 80 con una selección de punk, música electrónica, new romantic, etc. Entre los éxitos de Duran Duran, Depeche Mode o The Stranglers, entre otros, de esta época se camuflan temas de los 90 y de los 2000 creando una atmósfera musical de excepción para acompañar la eclosión y revolución de la informática de usuario.

\subsection{Rupturas expresivas}

Al igual que producciones cinematográficas como María Antonieta de Sofía Coppola (2006), series como Reign (CW, 2013-2017) han integrado la música como un elemento transgresor alternando música incidental convencional con canciones de billboard adecuadas al tono juvenil de la serie y de su público. Estos temas contemporáneos también forman parte de la música de pantalla compartiendo el salón de baile, por ejemplo, con otras composiciones cuya forma e instrumentalización nos parecen más próximos del momento (1557). Así, como afirma Sáez González (2007), Reign se libera por fin de los rígidos corsés del género histórico sin por ello renunciar a toda verosimilitud espacio-temporal.

Este tipo de inclusión de temas actuales dentro y fuera de los espacios en los que tiene lugar la acción supone una licencia creativa que aporta al relato una nueva lectura. En el caso de Reign (CW, 2013-2017) la inclusión de éxitos musicales contemporáneos pretende su vínculo con los personajes y, en cierto modo, la acción más que con el contexto histórico.

Ya desde la apertura de la serie el folk-rock de Scotland de The Lumineers nos advierte como espectadores su carácter transgresor como metonimia de la propia joven. Más que una reina con un pacto de matrimonio en la corte francesa María Estuardo es una adolescente que, junto a su grupo amigas (damas de compañía) acude a conocer el amor. Por ello sus andanzas estarán acompañadas de música coherente con el momento histórico así como una selección de temas preexistentes coherentes con la edad de las jóvenes y el género romance-drama adolescente de la serie.

Asimismo la selección de canciones, que incluye temas como Back to you de Twin Forks, Follow de Crystal Fighters o Girl Your're alright de Paul Otten, aportan nuevas lecturas a la secuencia que acompañan a través de sus letras.

Algunos de estos rasgos que caracterizan el scoring de Reing, van a estar presentes en otras series de ambientación histórica Peaky Blinders (BBC Two, 2013- )The Knick (Cinemax, 2014-2015) aunque con un grado de virtuosismo mayor tanto en la introducción y empleo de la música como en su integración con el discurso visual. Ambas producciones comparten momento histórico: The Knick se sitúa en la primera década del siglo XX en Nueva York,en torno a 1907 si se atiende a la aparición de Mary Tifoidea, y Peaky Blinders en el Birminghan inmediatamente posterior a la I Guerra Mundial, contienda cuyos fantasmas todavía atormentan a los excombatientes en las trincheras.

Desde una perspectiva musical ambas series cuentan con una construcción completamente diferente a pesar del cuidado trabajo de estas producciones, casi se 
podría considerar preciosismo, para dotar de realismo a la ambientación histórica (tanto el Knickerbocker Hospital como los peaky blinders existieron de verdad).

Así se puede hablar de una ruptura de las convenciones musicales para la época y el género audiovisual al que pertenecen, con una finalidad claramente expresiva; una ruptura que se consigue a través de dos vías diferentes: el scoring original de la serie y la integración de temas preexistentes.

Así el discurso musical de Peaky Blinders está compuesto por un importante número de canciones de rock contemporáneo de autores como Nick Cave, Jack White, The White Stripes, Tom Waits, Jonhy Cash, Laura Marling, Radio Head, Dan Auerbach o Artic Monkeys; algunos muy recientes como Lazarus de David Bowie o You Want it Darker de Leonard Cohen (ambos de 2016). Se trata de una selección ecléctica que se integra perfectamente en unas secuencias ambientadas más de seis décadas antes.

El opening de la serie con el tema Red right hand de Nick Cave \& Bad Seeds (1994), una canción oscura de rock alternativo que se inspira en el Paradise Lost de John Milton para hablar de venganza divina, constituye una verdadera declaración de intenciones tanto en el plano creativo como en el de la intertextualidad.

De hecho la serie logra hacer suya la selección musical integrándola en el montaje [y adaptándolo] como un elemento más del discurso visual, lo que le aporta valor así como una serie de sentidos y significaciones que transcienden los de la propia canción; los de la propia imagen.

Un ejemplo de ello lo encontramos al comienzo quinto episodio de la tercera temporada cuando el tema Lazarus de Bowie nos traslada al espacio interno subjetivo de un Tommy que se debate entre la vida y la muerte. Además de la expresividad de su montaje y tratamiento el tema de Bowie presenta una adaptación perfecta a la situación que vive el personaje hasta el punto de convertirse en su voz. En otro momento, también en el mismo capítulo, será la voz de Cohen la que se adelante a la pantalla cuando canta You Want it Darker durante la escena de la asfixia erótica.

Por el contrario en The Knick la ruptura expresiva no se fundamenta en una selección de música pregrabada sino en un scoring original, compuesto por Cliff Martínez, que acompaña y enfatiza el relato. La sinestesia entre imagen y música se concreta en el título de las composiciones: el mismo que el episodio al que acompañan. Así el tema del primer episodio se titula Son of placenta previa. Otros temas igualmente sugestivos son: Abscess, Aortic aneurysm junior, Most contagious thing on earth o New standard hernia procedure.

La música en The Knick llega antes que la imagen. Así los capítulos comienzan con unos segundos en negro aunque con un fondo sonoro que nos resulta inquietante como espectadores. De hecho la serie carece de cabecera al uso, sorprendiéndonos desde los primeros segundos de la temporada con un drone electrónico que integra sonidos ambiente y voces cuyo ritmo se acelera con la acción, adaptándose a la perfección, a la sucesión de imágenes. El estrecho vínculo entre música e imagen, especialmente en lo que se refiere a ritmo e intensidad, en ocasiones puede llevar a su identificación como un sonido subjetivo que replica el del corazón del protagonista especialmente en aquellos momentos en el que Dr. John W. Thackery se inyecta una dosis de cocaína. 
El carácter simbiótico de discurso musical y visual resulta sorprendente especialmente si se parte de que la música de The Knick es totalmente electrónica. En un relato que cuida al máximo la estética del momento, especialmente en lo que respecta a un ámbito tan especializado como la cirugía, el empleo de música anacrónica supone una ruptura expresiva que lo dota de una mayor expresividad. Parecería que en lugar de acompañar al momento histórico se construye sobre la base del personaje, de su vida al límite y de sus prácticas, en tanto que dicha construcción se ajustaría más a nuestra cultura audiovisual.

En palabras de Steven Soderbergh (en Grow, 2014), artífice de la serie, "Estéticamente, era un periodo verdaderamente atractivo, pero la música era absolutamente aburrida y no interesante. Acababa de comenzar el ragtime -y hay algo de éste en el fondo de algunas escenas- pero además de dicho estilo no había nada bueno"

La integración de esta música en el relato audiovisual y su injerencia en nuestra percepción, como espectadores del discurso visual, nos obliga a trascender la clasificación de Gorbman en torno a la música diegética o no diegética atendiendo a su ubicación respecto a la imagen.

Esta ruptura no tiene que ver tanto con la capacidad de localizar la fuente musical en foso o en pantalla, debido a que las posibilidades actuales de tratamiento del sonido permiten distinguir perfectamente la música afectada por el tiempo-espacio donde se inserta (siempre que así lo quiera el realizador o el sound designer), como con la consideración de la injerencia que música diegética o música no-diegética pueden tener en el desarrollo del relato. De hecho la recepción de The Knick sería completamente diferente sin la música que lo acompaña, a pesar de que ésta suena siempre fuera del espacio donde se mueven los personajes.

\subsection{La música como esencia de la serie}

La categorización propuesta en este artículo pretende dar cabida a la ambientación musical de las diversas series de época, incluso de aquellas de género fantasía o ciencia ficción situadas en un espacio físico-temporal inexistente aunque con elementos que recuerdan a un momento determinado (o a la construcción audiovisual de un momento determinado). Así el scoring de Game of Thrones (HBO, 2011- ) apela a la concepción que tenemos como espectadores de la ambientación de una época medieval y una trama de lucha de poder-conquista.

Del mismo modo la música de series como Penny Dreadful (Showtime, 2014-2016) o Davinci's Demons (Starz, 2013-2016) cumple con las expectativas de los espectadores para el momento que recrean -el Londres victoriano y la Florencia renacentista, respectivamente- aunque incluyen rasgos musicales, como la selección de un modo menor o el empleo de determinadas cadencias, que nos generan cierta inquietud y que reflejan el carácter mágico, misterioso o tétrico del espacio en el que se transitan y se relacionan los personajes.

Mención aparte exigen otras series cuyo scoring podría encuadrarse en las primeras categorías aunque va más allá para asumir un papel nuclear tanto para ambientar el momento-espacio donde tiene lugar la acción ya para la construcción integral del propio relato. 
Este es el caso de Life on Mars (BBC, 2006-2007) o de su continuación Ashes to ashes (BBC, 2008-2010), dos miniseries producidas por la BBC cuyos nombres se corresponden con dos canciones de David Bowie. Aunque se encuadran en el género ciencia ficción ambas series están ambientadas en momentos y espacios reales Manchester de la década de los 70 y Londres de principios de los 80- lo que va a proyectarse en du selección musical.

Sam Tyler, el protagonista de Life on Mars, escucha en 2006 el tema del mismo nombre en su iPod antes del accidente que lo traslada a 1973 sin que la canción deje de sonar (sí se va a percibir el tratamiento pasando de música digital diegética, a interior, extradiegética y vuelta a la pantalla aunque con una sonoridad propia de una autorradio del momento). Dentro del scoring de la serie, compuesto por diversos temas del momento, la canción de Bowie se convierte en una suerte de leitmotiv que acompañará al personaje a lo largo de los episodios. En este caso la conexión entre discurso musical y audiovisual es perfecta y está llena de intertextualidad: al igual que señala la letra de la canción, Tyler tendrá que acomodarse a esta nueva realidad en la que él es un extraño, casi un extraterrestre.

La sensación de venir de otro planeta, sugerida en alguna ocasión por el protagonista, será explotada en su adaptación estadounidense (ABC, 2008-2009). Una adaptación que, como sucedió con la española La chica de ayer (Ida y vuelta, 2009), continúan apelando a este vínculo musical aunque con una integración menor en su relato.

En Ashes to Ashes (BBC, 2008-2010) la detective Alex Drake un tiro en la cabeza la trasladará a 1981, un año después del lanzamiento de la canción. Esta serie presenta una selección musical ecléctica con temas de Duran Duran, The Clash o Supertramp y combinando estilos comocomo punk, new romantic, synthpop, pop, ska o glam rock, entre otros.

\section{DISCUSIÓN}

La cuidada construcción de la ficción serial en la llamada Quality TV se ha reflejado en la concepción de su ambientación musical. De la idea de banda sonora como una música incidental aunque con una función expresiva y estructurante, se ha pasado a una concepción integral del relato audiovisual.

Cada vez más las series emplean la música para establecer el espacio -físico o temporal-, sentido, estilo del relato e incluso para vehicular partes del mismo dotando de sentido a la imagen.

En el caso concreto de las series de época la música ha pasado de ser un acompañamiento de la imagen a incidir en ésta, dotando de realismo a la ambientación histórica y aportando nuevas lecturas. Esta circunstancia se hace especialmente patente en series como Peaky Blinders o The Knick en las que el valor añadido de la música es clave para la construcción del relato.

A pesar de que la música original puede emular el estilo y sonoridad de una determinada época respondiendo a las expectativas -y a la cultura audiovisual- de los espectadores para dicho momento, es el empleo de temas pregrabados el que logra unos resultados más interesantes. 
La selección de temas preexistentes funciona a modo de anclaje con el momento histórico, especialmente en las últimas décadas, dada la mayor capacidad de concreción temporal y el afecto que suscitan estos temas en los espectadores. Asimismo la integración de este tipo de músicas acarrea sus propios marcos de referencia y también sus propios significados vinculados a la letra.

La entidad que adquiere el scoring de estas series en nuestra experiencia como espectadores, en el proceso de decodificación del momento histórico, los espacios o los personajes, hace precisa una revisión de los conceptos de diegético y no-diegético desde una perspectiva sonora.

La distinción propuesta por Gorbman (1980) carece de sentido en el abordaje contemporáneo de la música en las series televisión, especialmente si se atiende a la implicación del concepto no-diegético desde una persectiva narratológica. Como señala Winters (2010) Gorbman parece no contemplar la posibilidad de que la música no diegética pueda constituir parte de la narrative más que una intrusión o un acompañamiento externo; una posibilidad que resulta cada vez más patente en las producciones televisivas.

En definitiva, con independencia de su localización en las series de ambientación histórica la selección musical establece una dialéctica compleja con la imagen construyendo un universo estético, narrativo o emocional paralelo a partir de las intenciones e intersecciones del repertorio de canciones y su injerencia en la percepción subjetiva de los espectadores.

\section{REFERENCIAS}

Altman, R. (2007). Silent Film Sound. New York: Columbia University Press.

Brown, R. S. (1994). Overtones and Undertones: Reading Film Music. Berkeley: University of California Press.

Calderón, D.; Gustems, J. \& Duran, J. (2016). La música y movimiento en Pixar: Las UST como recurso analístico. Vivat Academia. Revista de Comunicación, 136, 82-94. doi: https://doi.org/10.15178/va.2016.136

Chion, M. (1993). La audiovisión: introducción a un análisis conjunto de la imagen y el sonido. Barcelona: Paidós.

Copland, A. (1988). What to Listen for in Music. New York: McGraw-Hill.

Gorbman, C. (1980). Narrative Film Music. Yale French Studies, 60, 183-203. doi: http://dx.doi.org/10.2307/2930011

Grow, J. (2014). Blood Brothers: Inside the Music of 'The Knick'. Rolling Stone. Retrieved from https://goo.gl/Yv15sp

Jancovich, M. \& Lyons, J. (2003). Quality Popular Television: Cult TV, the Industry and Fans. London: British Film Institute.

Kelly, C. R. (2016). The Toxic Screen: Visions of Petrochemical America in HBO's True Detective (2014). Communication, Culture \& Critique, 9(3), 1-19 (Early preview). doi: http://dx.doi.org/10.1111/cccr.12148

Lack, R. (1999). La música en el cine. Madrid: Cátedra.

Piñeiro Otero, T. (2016). Intentions and intersections of classical music in Bryan Fuller's Hannibal (NBC). L'Atalante, 21, 177-189. Recuperado de: https://goo.gl/3qXFph Consultado el 10 de octubre, 2017. 
Powrie, P. \& Stilwell, R. (2006). Changing Tunes: The Use of Pre-existing Music in Film. Burlington: Ashgate Publishing Company.

Prendergast, R. (1992). Film Music, A Neglected Art. The history and techniques of a new art form, from silent films to the present days. New York: Norton.

Richardson, J. y Gorbman, C. (2013). The Oxford handbook of New Audiovisual Aesthetics. New York: Oxford University Press.

Samuels, D. W.; Meintjes, L.; Ochoa, A.M. \& Porcello, T. (2010). Soundscapes: Toward a sounded anthropology. Annual Review of Anthropology, 39, 329-345. doi: http:/ / dx.doi.org/10.1146/ annurev-anthro-022510-132230.

Schafer R. M . (1993). The soundscape: our sonic environment and the tuning of the world. Rochester: Destiny Books.

Schwachter, J. (2010). The Sounds of 'Boardwalk Empire'. Altantic City Weekly. Retrieved from https://goo.gl/1djX3s

Torelló, J. \& Duran, J. (2014). Michel Chion in Audio-Vision and a practical approach to a scene from Andrei Tarkovsky's Nostalghia. L'Atalante, 18, 111-117. Retrieved from https://goo.gl/d7PV3x

Visa Barbosa, M. (2011). Claves del éxito del personaje psicópata como protagonista en el cine. Vivat Academia. Revista de Comunicación, 116, 40-51. doi: https://doi.org/10.15178/va.2011.116

Whiteley, S. (2004). 'Introduction', en Whiteley, S., Bennett A. \& Hawkins, S. (Eds.). Music, Space and Place: Popular Music and Cultural Identity (pp. 2-8). Aldershot: Ashgate.

Whittaker, Tom (2012). Mobile soundscapes in the quinqui film, In L. Shaw \& R. Stone, (Eds.). Screening songs in Hispanic and Lusphone Cinema (pp.98-113). Manchester, Manchester University Press.

Winters, B. (2010). The non-diegetic fallacy: Film, music, and narrative space. Music and Letters, 91(2), 224-244. doi: 10.1093/ml/gcq019

Wright, R. (2003). Sore vs. Song: Art, Commerce, and The H Factor in Film and Television Music. In I. Inglis, I. (Ed.). Popular Music and Film (pp. 8-21). London: Wallflower Press.

\section{AUTORA}

\section{Teresa Piñeiro Otero}

Licenciada en Publicidad y Relaciones Públicas por la Universidade de Vigo y doctora en Comunicación por la misma universidad. Profesora del Departamento de Sociología y Ciencias de la Comunicación de la Universidade da Coruña. Ha orientado su investigación hacia las nuevas manifestaciones sonoras en la red, así como a las nuevas narrativas en el ámbito de la convergencia. En esta línea ha realizado una estancia de investigación sobre la música en las series en la Cátedra de Sonido Costantini, de la Universidad de Buenos Aires, con una Beca Iberoamérica de Santander Universidades.

https://orcid.org/0000-0001-6414-2700 